than $4 \%$ describing restrictions. With regard to the newer drugs, the positions seemed to be more mixed, although $44 \%$ suggested that usage was currently unrestricted and $20 \%$ did not know what the position was.

The practice of involving general practitioners (GPs) in the prescription of clozapine did not seem to be widespread, with less than $4 \%$ of the sample indicating that GPs regularly took over the prescribing costs and a further $16.2 \%$ saying that they occasionally did so. Over $50 \%$ of the sample indicated that GPs did not take any part in this practice.

\section{Type of trust and clozapine usage}

In line with the original hypothesis, replies were divided into those from trusts where mental health was combined with acute services ( $n=31)$ and those where it was not $(n=72)$. The latter included combined mental health and community services. Although a slightly greater proportion of trusts where there was difficulty in obtaining clozapine were of the type mental health plus acute $(4 / 31$ v. 6/72), the difference was not significant (Fisher's exact test: $P=0.34$, d.f.=1). Thus, there were no grounds for the belief that acute trusts were detrimental to their mental health units' prescribing freedom where clozapine was concerned.

\section{Comment}

With a response rate of over $80 \%$, four-fifths of whom described themselves as general psychiatrists, the method, although not perfect, was reasonably successful in reaching its target audience. Clozapine usage seems ubiquitous, with nearly half of the respondents using it for cases beyond the narrow criteria of treatment resistance.

The results of the survey are generally optimistic, with few respondents reporting difficulties in obtaining any of the drugs. However, there was very little to suggest that GPs are currently taking up any of the prescribing burden for clozapine. This does not bode well for the future if hospital prescribing budgets do not expand to meet the needs of new candidates for clozapine therapy, and any expansion at the moment must be seen as highly unlikely.

It would be useful to see the results of this survey as a benchmark and to repeat it at regular intervals to monitor any restrictions on the use of these drugs.

\section{References}

ATrchison, K. J. \& KERWIN, R. W. (1997) Cost effecttveness of clozapine. A UK clinic-based study. British Joumal of Psychiatry, 171, 125-130.

Healy, D. (1993) Psychopharmacology and the ethics of resource allocation. Brttish Journal of Psychiatry, 162. 23-28.

LAUNER, M. (1995) Clozapine in schizophrenia. Lancet, 345. $1435-1436$.

MEDICAL DIRECTORY (1996) The Medical Directory 1996. London: Cartermill International Ltd.

MelTZER, H. Y. \& COLA, P. A. (1994) The pharmacoeconomics of clozapine. Joumal of Clinical Psychiatry. 68 (suppl. B), 161-165.

M. F. Bristow, Consultant and Senior Lecturer on Community Psychiatry, Cheam Resource Centre, 671 London Road, North Cheam SM3 9DL

\title{
Early experience of the use of olanzapine across three rehabilitation services
}

\section{Paul Wolfson, Carol Paton, Phillip Steadman, Humphrey Needham- Bennett and Susan Cope}

\begin{abstract}
Ams and method To monitor the effect of the introduction of olanzapine under naturallistic

conditions to patients with severe and enduring mental illness in three rehabilitation services.
\end{abstract}


Reaults Thirty patients were prescribed olanzapine during the first six months of its launch. Objective ratings were used. Six months later, one-third were no longer on treatment, one-third were unchanged and one-third had made useful clinical gains.

Clinical implications Patlents who have suffered from neurological or prolactin-related side-effects may benefft from treatment with olanzapine. Attitudes to treatment and adherence may improve.

Rehabilitation services provide exclusively for a relatively small number of known patients with enduring mental illness who present intractable and often distressing problems for themselves and their carers. Such patients require long-term treatment either in hospital or in highly staffed community accommodation, placing a considerable burden on the National Health Service (NHS) (Davies \& Drummond, 1994). Small improvements in this patient group can be very significant clinically and have major implications for resources. There is a continuing search for new treatment strategies, and new antipsychotic drugs are often given first to this group of patients despite the paucity of evidence for their efficacy in treatment refractory illness (Taylor et al, 1997).

Olanzapine is an atypical antipsychotic drug that was introduced into the UK in November 1996. Although it is sedative and is associated with weight gain. olanzapine has a very low incidence of extrapyramidal side-effects and is virtually free from prolactin-related side-effects (Tollefson et al, 1997), both of which are factors that may improve attitudes towards medication, and hence adherence - a major problem in this group of patients. Patients' attitudes towards medication are rarely considered during clinical trials, but can be measured in clinical settings using the Rating of Medication Influences Scale (ROMI: Weiden et al, 1994), which includes a number of items known to predict both adherence and non-adherence.

The aim of this study was to observe the use of olanzapine in rehabilitation services in the first six months after its launch in the UK, and to describe the outcome for patients for whom it was prescribed.

\section{The study}

All patients under the care of rehabilitation psychiatrists in the London Boroughs of Bexley. Greenwich, Lewisham and North Southwark who were prescribed olanzapine at any time during the first six months after its launch (November 1996-April 1997) were included in the study.

Prior to starting olanzapine, the following data were collected: age, gender, ethnicity, diagnosis, age when first ill, duration of illness and time spent in hospital since diagnosis, current medication and the consultants reason for prescribing olanzapine. At baseline and after six months, the Brief Psychiatric Rating Scale (BPRS; Overall \& Gorham, 1962), Barnes Akathisia Scale (BAS; Barnes, 1989), Simpson-Angus Scale (SAS; Simpson \& Angus, 1970) and Clinical Global Impression (CGI; Guy, 1976) of severity were completed by a psychiatrist from the prescribing clinical team. The ROMI was administered by a pharmacist (C.P.) who was independent of the ongoing clinical care of the patient. All prescribed medication was recorded. Owing to practical difficulties, patients who did not complete six months of treatment were not re-interviewed.

Individual items on the ROMI at baseline for those who completed six months of treatment and those who did not were compared using unpaired $t$-tests. For those who completed six months of treatment, individual items were compared at baseline and end-point using paired t-tests.

\section{Findings}

\section{The population}

Thirty patients were prescribed olanzapine. Fifteen were male and 15 female. Twenty-one were Caucasian and nine were of African or AfroCaribbean origin. Twenty-four had a diagnosis of schizophrenia and six of schizoaffective disorder. Their mean age was 45 years (s.d. $=13$; range $=20$ 74) and the mean duration of hospitalisation was 11 years (range: 2 months -43 years). The mean BPRS score was 31.5 (s.d.=14.5; range=9-68) and the mean CGI severity score on the sevenpoint scale was 4.7 (s.d.=1; range=3-7).

Twenty-four patients were in hospital, four were in residential settings with 24-hour staff cover and two were living at home with intensive community support. One patient was medication free, 13 were recetving risperidone, 14 were recetving a typical neuroleptic and two were recetving clozapine. Nine were taking more than one antipsychotic and 14 were taking other concomitant psychotropic medication (benzodiazepines, lithium, carbamazepine, antidepressants).

\section{Reason for prescribing olanzapine}

Eighteen patients were prescribed olanzapine because of failure to respond adequately to current medication (four had falled to respond to clozapine either currently or previously), four because of fallure to tolerate previous treatments (including three clozapine neutropenias) and eight because of failure to respond and side-effects.

Flve patients had failed to tolerate all previously prescribed antipsychotics and 25 had 
Table 1. Baseline patient characteristics and outcomes after six months of treatment with olanzapine

\begin{tabular}{llcc}
\hline & Non-completers & Non-responders & Responders \\
\hline Number of patients & 10 & 8 & 12 \\
Baseline BPRS' & $32.7(15.3)$ & $32.8(13.7)$ & $29.3(13.5)$ \\
Age at onset of illness' & $22(11.5)$ & $22.3(8.4)$ & $20.4(5)$ \\
Duration of illness' (years) & $24.7(11.4)$ & $17.3(10.7)$ & $26.5(7.2)$ \\
Treatment intolerant & 1 & & 4 \\
Treatment resistant & 9 & 8 & 8 \\
BPRS at end-point' & & $33.6(10.6)$ & $23.6(12.2)$ \\
Mean improvement & & $-2.4 \%$ & $19.5 \%$ \\
\hline
\end{tabular}

BPRS, Brief Psychiatric Rating Scale.

1. Values are means with standard deviations in parentheses.

Table 2. Changes in Rating of Medication Influences Scale (ROMI) scores after six months of treatment with olanzapine

\begin{tabular}{llll}
\hline & $\begin{array}{l}\text { Mean ROMl score } \\
\text { before treatiment (s.d.) }\end{array}$ & $\begin{array}{l}\text { Mecn ROMl score affer } \\
\text { treatment (s.d.) }\end{array}$ & $p$ \\
\hline Denial of the illness & $2.25(0.59)$ & $1.8(0.8)$ & 0.14 \\
Denial of the benefits of medication & $1.8(0.7)$ & $1.5(0.7)$ & 0.05 \\
Percelve staff as opposed to medication & $1.6(0.5)$ & $1.15(0.4)$ & 0.008 \\
Percelve family as positive about medication & $2.0(0.9)$ & $2.7(0.7)$ & 0.23 \\
Percelved distress from side-effects & $2.15(0.8)$ & $1.0(0.5)$ & 0.015 \\
\hline
\end{tabular}

For all ROMI items: 1=none, 2=mild bellef, 3=strong bellef.

falled to respond in that they had no period of good functioning over the last five years.

\section{Outcomes}

Ten patients did not complete six months of treatment, eight of whom took olanzapine for less than one week. At the six-month follow-up, three of these patients were unchanged, three had been involved in aggressive incidents that had led to their transfer to more secure accommodation, one had been readmitted to hospital under the Mental Health Act and one had been administered clozapine against their will. A further patient was withdrawn for medical reasons (symptoms pre-dated olanzapine and withdrawal was a precautionary measure) and one patient died due to a chronic medical condition unrelated to olanzapine use.

Twenty patients completed six months of treatment with olanzapine. On the CGI scale, four were rated to have very much improved, eight to have much improved and eight to have improved minimally or be no different. Baseline patient characteristics and outcomes from treatment are shown in Table 1 . At the end-point, 10 patients were receiving olanzapine alone, four were receiving olanzapine and haloperidol and the remaining six were receiving olanzapine and other psychotropic medication (benzodiazepines, lithium, carbamazepine, antidepressants). The mean dose of olanzapine was $16 \mathrm{mg}$.

\section{Side-effects}

The mean SAS score reduced from 1.6 (s.d.=2.3) at baseline to 1.1 (s.d.=2.8) at six months, and the mean BAS score reduced from $2(s . d .=2.8)$ at baseline to 0.3 (s.d. $=0.6$ ) at six months.

\section{Patients' perceptions}

Of the 20 patients who completed six months of treatment, 16 were able to at least partially complete interviews, two were too thought disordered and two refused.

Rating of Medication Influences Scale (ROMI)

Non-completers at baseline were more likely to perceive pressure to take medication $(P=0.026)$, prefer illicit drugs to prescribed medication $(P=0.12)$, be distressed by side-effects $(P=0.018)$, perceive their family as opposed to medication $(P=0.08)$ or have a negative relationship with their psychiatrist $(P=0.08)$.

Post-treatment changes in the completers are shown in Table 2.

\section{Comment}

Naturalistic studies are valuable to clinicians because they indicate whether the results of Phase 3 outcome studies are generalisable to the patient populations treated in clinical practice. The majority of our patients would not have been 
eligible for inclusion in such outcome studies because of problems with giving informed consent or fitting other exclusion criteria. Our patients received a mean dose of $16 \mathrm{mg}$ of olanzapine and one-fifth also received other antipsychotics, in line with the findings of a large survey by Taylor et al (1998).

The mean reduction in BPRS scores following treatment with olanzapine was $19.5 \%$ in the 12 patients rated as making a worthwhile clinical response, and did not reach the conventional $20 \%$ threshold for response normally used in pharmacological outcome studies (Meltzer, 1992). These improvements in mental state, although modest, were clinically significant. Other factors not detected by the BPRS may be very important. For example: reduced negative attitudes towards medication in those who completed six months of treatment may have significant implications for future management in that patients were less likely to deny that they were ill, or that medication could help, and perceived both staff and their family as being more supportive, irrespective of whether they were rated as being clinically improved or not. Extrapyrammidal side-effects and akathisia were both reduced but the group who were rated to have very much improved had all failed to tolerate other treatments, due to prolactinrelated side-effects (impotence, galactorrhoea and amenorrhoea). Two patients in this group were discharged into community settings and both continued to take olanzapine with staff support; this was the first time either had taken antipsychotic medications whilst not being subject to the Mental Health Act.

Longer term follow-up will be necessary to determine whether reduced symptoms and sideeffects and improved attitudes to treatment lead to improvements in social functioning and placement in less-supervised settings.

\section{References}

BARNES, T. R. E. (1989) A rating scale for drug-induced akathisia. British Journal of Psychiatry. 184, 672-676.

DAVIES, L. M. \& DRUMMOND, M. F. (1994) Economics and schizophrenia: the real cost. Brtish Journal of Psychiatry, 165 (suppl. 25), 18-21.

GUY. W. (1976) The Clinical Global Impression Scale. ECDEU Assessment Manual for Psychopharmacology, revised DHEW Publ. No. (ADM) 78-388. Rockville, MD: National Institute of Mental Health.

MELTZER, H. Y. (1992) Dimensions of outcome with clozapine. Brttish Journal of Psychiatry. 160 (suppl. 17). 46-53.

OVERALL, J. E. \& GoRHAM, D. R. (1962) The Brief Psychiatric Rating Scale. Psychological Reports, 10, 799-812.

SimpSON, G. M. \& ANGUS, J. W. S. (1970) A rating scale for extrapyramidal side-effects. Acta Psychiatrica Scandinavica, 212 (suppl. 1), 11-19.

TAYOR, D., HOLMES, R., HIITON, T., et al (1997) Evaluating and improving the quality of risperidone prescribing. Psychiatric Bulletin, 21, 680-683.

-. DRUMmond, S. \& PENDLEBURY, J. (1998) Olanzapine in practice. Psychiatric Bullettr, 22, 552-554.

Tollerson, G. D.. Beasley, C. M. Tran, P. V., et al (1997) Olanzapine versus haloperidol in the treatment of schizophrenia and schizoaffective and schizophreniform disorders: results of an international collaborative trial. American Joumal of Psychtatry. 164, 457-465.

WEIDEN, P., RAPKIN, B., MOTT, T., et al (1994) Rating of Medication Influences (ROMI) Scale in schizophrenta. Schizophrenia Bullettr, 20, 297-310.

Paul Wolfson, Consultant in Rehabilitation Psychiatry. "Carol Paton, Principal Pharmacist, Oxdeas NHS Trust, Pharmacy Department, Bexdey Hospital, Old Bexley Lane, Bexley, Kent DA5 2BW; and Phillip Steadman, Senior Registrar in Psychiatry, Oxleas NHS Trust, Humphrey Needham-Bennett, Senior Registrar in Psychiatry and Susan Cope, Consultant in Rehabilitation Psychiatry, Guy's \& Lewisham NHS Trust

*Correspondence 